\title{
Real-Time Environmental Monitoring for Aquaculture Using a LoRaWAN-Based IoT Sensor Network
}

\author{
Harvey Bates*D, Matthew Pierce and Allen Benter \\ NSW Department of Primary Industries, Orange Agricultural Institute, Orange, NSW 2800, Australia; \\ matt.pierce@dpi.nsw.gov.au (M.P.); allen.benter@dpi.nsw.gov.au (A.B.) \\ * Correspondence: harvey.bates@dpi.nsw.gov.au
}

Citation: Bates, H.; Pierce, M.; Benter,

A. Real-Time Environmental

Monitoring for Aquaculture Using a

LoRaWAN-Based IoT Sensor

Network. Sensors 2021, 21, 7963.

https://doi.org/10.3390/s21237963

Academic Editors: Dimitrios

Piromalis, Konstantinos G. Arvanitis and Panagiotis Papageorgas

Received: 24 October 2021

Accepted: 28 November 2021

Published: 29 November 2021

Publisher's Note: MDPI stays neutral with regard to jurisdictional claims in published maps and institutional affiliations.

Copyright: (c) 2021 by the authors. Licensee MDPI, Basel, Switzerland. This article is an open access article distributed under the terms and conditions of the Creative Commons Attribution (CC BY) license (https:// creativecommons.org/licenses/by/ $4.0 /)$.

\begin{abstract}
IoT-enabled devices are making it easier and cheaper than ever to capture in situ environmental data and deliver these data-in the form of graphical visualisations- to farmers in a matter of seconds. In this work we describe an aquaculture focused environmental monitoring network consisting of LoRaWAN-enabled atmospheric and marine sensors attached to buoys on Clyde River, located on the South Coast of New South Wales, Australia. This sensor network provides oyster farmers operating on the river with the capacity to make informed, accurate and rapid decisions that enhance their ability to respond to adverse environmental events-typically flooding and heat waves. The system represents an end-to-end approach that involves deploying a sensor network, analysing the data, creating visualisations in collaboration with farmers and delivering them to them in real-time via a website known as FarmDecisionTECH ${ }^{\circledR}$. We compared this network with previously available infrastructure, the results of which demonstrate that an in situ weather station was $\sim 5^{\circ} \mathrm{C}$ hotter than the closest available real-time weather station $(\sim 20 \mathrm{~km}$ away from Clyde River) during a summertime heat wave. Heat waves can result in oysters dying due to exposure if temperatures rise above $30^{\circ} \mathrm{C}$ for extended periods of time (such as heat waves), which will mean a loss in income for the farmers; thus, this work stresses the need for accurate in situ monitoring to prevent the loss of oysters through informed farm management practices. Finally, an approach is proposed to present high-dimensional datasets captured from the sensor network to oyster farmers in a clear and informative manner.
\end{abstract}

Keywords: LoRaWAN; IoT; aquaculture; environment; monitoring

\section{Introduction}

Oysters are filter feeding bivalve molluscs that have hard calcified shells [1]. These organisms live in the intertidal and subtidal zones of many river systems, feeding on phytoplankton present in the upper water column where sunlight is available for photosynthesis [1,2]. Oysters are farmed globally, mainly for human consumption, and represent a significant proportion of global aquaculture production [3]. In Australia, the aquaculture industry is currently on the rise, and has an estimated net worth of $\$ 1.5$ billion in 2021 [4]. This rise is primarily being driven by increasing consumer incomes and an increasing awareness on the positive effects of responsible aquaculture practices [3]. Oyster farming exists as one of the key components of Australia's aquaculture industry, and within New South Wales (NSW) this industry accounts for $65 \%$ (\$58.2 million) of total aquaculture production (in 2019/20) [4,5].

Oyster production provides valuable socio-economic and cultural benefits to local communities; however, as with any type of farming, oyster farming comes with inherent risks, such as disease outbreaks, pest invasion (e.g., mudworm-Polydora websteri or flatworm-Imogine mcgrathi) and negative environmental effects, such as flooding and heat waves [6-9]. These environmental factors have a significant effect on (1) the overall rate of oyster production, (2) the risk of food poisoning after consumption (e.g., norovirus) and (3) the risk that oysters may perish-especially younger oysters or vulnerable species [8-10]. 
As such, both farmers and consumers can suffer if appropriate management strategies are not in-place to prevent or minimise these risk factors.

The risk of mudworm or flatworm invasion can be contained by hanging oysters in the open air for several days [6,11]. However, this method is risky-especially in the summer months-as temperatures above $30{ }^{\circ} \mathrm{C}$ can be fatal [6]. Farmers can use accurate local weather information to improve farm management. If high temperatures are detected early enough, farmers can cool down their oyster leases by spraying the oysters with seawater, or when using flip-baskets outside of intertidal zones, inverting their oyster baskets back into the water $[6,12]$.

Heavy rainfall and subsequent flooding in the local or upper river system can have significant impacts on water quality. As oysters filter organic matter from the water column, they have the potential to ingest, and store for several days, bacteria (e.g., Escherichia coli), enteric viruses (Norovirus), heavy metals (e.g., lead, mercury, copper and zinc) and phytoplankton (e.g., cyanobactiera and diatoms) that pose a risk to human health $[2,13,14]$. These risks can be exacerbated when salinity in the water column decreases-as is the case after large rainfall events-and as such, the NSW Food Authority has implemented several regulations that halt oyster harvesting as a result of rainfall, sewage discharge, a phytoplankton bloom or low salinity $[2,13]$. Low salinity can have a significant effect on shellfish production as well, via reduced feeding and respiration rates as oysters shut their shells during these periods [15].

Real-time in situ data can provide significant benefits to the oyster industry as a means to enhance current farm management practices and provide early warnings for extreme weather events - such as heat waves and flooding. Additionally, these data could be used for future comparison under a changing climate. Real-time monitoring in agriculture and aquaculture is commonly employed to enhance farm management decisions [16,17]. However, the deployment of an environmental sensor network for monitoring estuaries presents several technical challenges that need to be addressed.

The first challenge to consider is the large sizes and properties of coastal estuaries that oyster leases typically occupy. As environmental conditions differ spatially, it is vital that multiple sensors are deployed to quantify the spatial variation in environmental variables, such as salinity [15]. However, this makes it difficult for real-time data to be captured remotely as commonly used cellular networks may not have sufficient signal across entire river systems (especially if the surrounding topography is varied). Alternatively, a low power wide area network (LPWAN) application, known as LoRaWAN, may be suitable for this function, as this form of communication enables the transfer of encrypted data over long distances (kilometres) while maintaining low-power consumption $[18,19]$. LoRaWAN requires a local receiving gateway to transfer the incoming packets to a network serverThe Things Network (TTN) (The Things Industries, Amsterdam, NL) - to be decoded, after which a formatted (JSON) object (data) can be forwarded to a back-end database for storage and/or a front-end server for visualisation. LoRaWAN-enabled devices have previously been deployed in smart cities, within the agricultural sector and as an automated technique to monitor and control aquaculture ponds, amongst many other applications [20-22].

Secondly, as the sensor network is to be deployed in a saline environment, corrosion of sensitive electrical components is likely. For this reason, keeping the system as low-cost yet durable as possible allows for replacement parts to be acquired and fitted readily in the infrequent cases of failure. Typically LoRaWAN devices are low-cost compared to other Internet of Things (IoT)-enabled devices with similar functions, such as narrow-band IoT (NB-IoT), making LoRaWAN nodes cheap to replace if necessary [23]. Additionally, biofouling of submerged sensors also impacts the accuracy of environmental monitoring, as readings can drift overtime due to fouled sensor units [24]. This issue, however, can be managed with regular maintenance and preventive measures [24].

In this work, we present a real-time approach for monitoring environmental conditions on and within river systems using IoT-enabled systems and a LoRaWAN sensor network. This network was deployed in 2019 on Clyde River, located on the Southern coast of 
NSW, Australia, in collaboration with local oyster farmers as a means to increase their adoption of newly available digital technologies. The Clyde River represents roughly $11 \%$ ( $\sim$ \$6.1 million) of NSW's total oyster production (in 2019-20) [5]. The sensor network consists of 10 buoys with submerged water quality sensors distributed from the head of the river at Batemans Bay, to the upper part of the estuary $-8 \mathrm{~km}$ from Batemans Bay. Additionally, a local LoRaWAN-enabled automatic weather station (AWS) was deployed to provide an accurate representation of current weather conditions. The weather station is compared to currently available infrastructure to demonstrate the need for accurate in situ environmental monitoring systems in order for farmers to make informed decisions. While multiple works describing aquaculture monitoring using IoT devices exist, they often fail to apply the technology in field, or to denote its use by farmers [25]. Other works describe their use in the field but focus on the technological aspects, such as transmission performance $[26,27]$.

The network produces a large amount of time-series and spatially resolved data which were automatically routed into an in-house developed data platform, known as FarmDecisionTECH ${ }^{\circledR}$. This platform was used to create alerts and graphical visualisations for farmers that are accessible using both mobile and cellular devices. This work aims to present an end-to-end approach, by describing how the network was deployed, the challenges faced, the importance of in situ monitoring, how these data were analysed to make their interpretation accessible for farmers and how these data were delivered to farmers in real-time.

\section{Methodology and Results}

\subsection{Location}

The Clyde River, located on the Southern Coast of NSW, Australia $\left(-35^{\circ} 42^{\prime} 30.3114^{\prime \prime}\right.$ $\left.150^{\circ} 10^{\prime} 39.3486^{\prime \prime}\right)$, was chosen based upon its prominence as one of the largest oyster farming regions in NSW (Figure 1) [5]. Eurobodalla Shire Council, the local council surrounding Clyde River, had recently constructed a LoRaWAN-enabled network in consultation with Meshed (Meshed Pty Ltd, NSW, AUS), as a part of their Smart Cities Initiative. This infrastructure includes a LoRaWAN gateway located on a radio tower on-top of Mt. Wandera ( $\sim 20 \mathrm{~km}$ from Clyde River).

The river system is divided up into three main areas: (1) Waterfall, (2) Rocky Point and (3) Moonlight harvesting area (Figure 1). These harvesting areas are subject to different environmental requirements, as outlined by the NSW Food Authority (Table A1). Fixed buoys were positioned throughout these harvesting areas to coincide with water quality sampling sites and in relation to oyster production and/or vulnerable locations. The location of these buoys was subject to NSW Marine Parks Approval (permit number MEA19/172) and limited their location to areas outside Sanctuary Zones or amongst seagrass communities. Additionally, NSW Roads and Maritime were consulted to ensure the buoys' positions were outside navigable waters and in conformity to the International Association of Marine Aids to Navigation and Lighthouse Authorities (IALA) (System A) special buoy requirements.

\subsection{Hardware}

Black buoys (Data Buoy 600, Smart Buoy Co., Bairnsdale, Australia) were deployed based on IALA special buoy guidelines (Figure 2). These buoys were custom built to include a $37.5 \mathrm{~mm}$ tube, which extends through the buoy, for routing cables and underwater sensors. The buoys were secured to a ballast chain which extends from the base of the buoy followed by a rope to a $140 \mathrm{~kg}$ concrete anchor. 


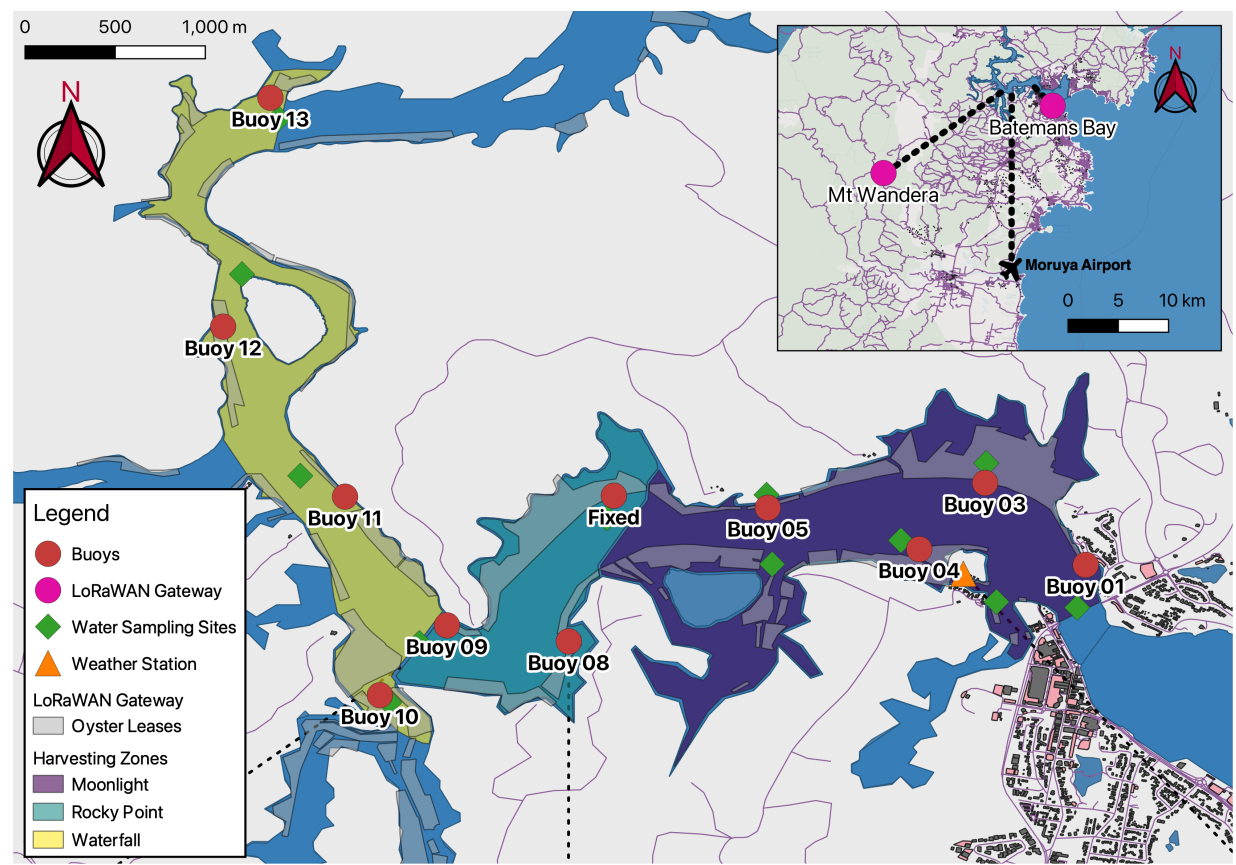

Figure 1. Locations of Clyde River and sensor network on the South Coast of NSW. Two maps of different scales are provided to represent the locations of deployed buoys (red circles) and other local developments, and the location of Batemans Bay in relation to Moruya Airport (black plane) and the regional LoRaWAN gateways (pink circles). Water sampling locations are represented as green diamonds, orange triangles represent weather stations, grey polygons define oyster leases and harvesting areas are indicated by purple (Moonlight), cyan (Rocky Point) and yellow (Waterfall) polygons.

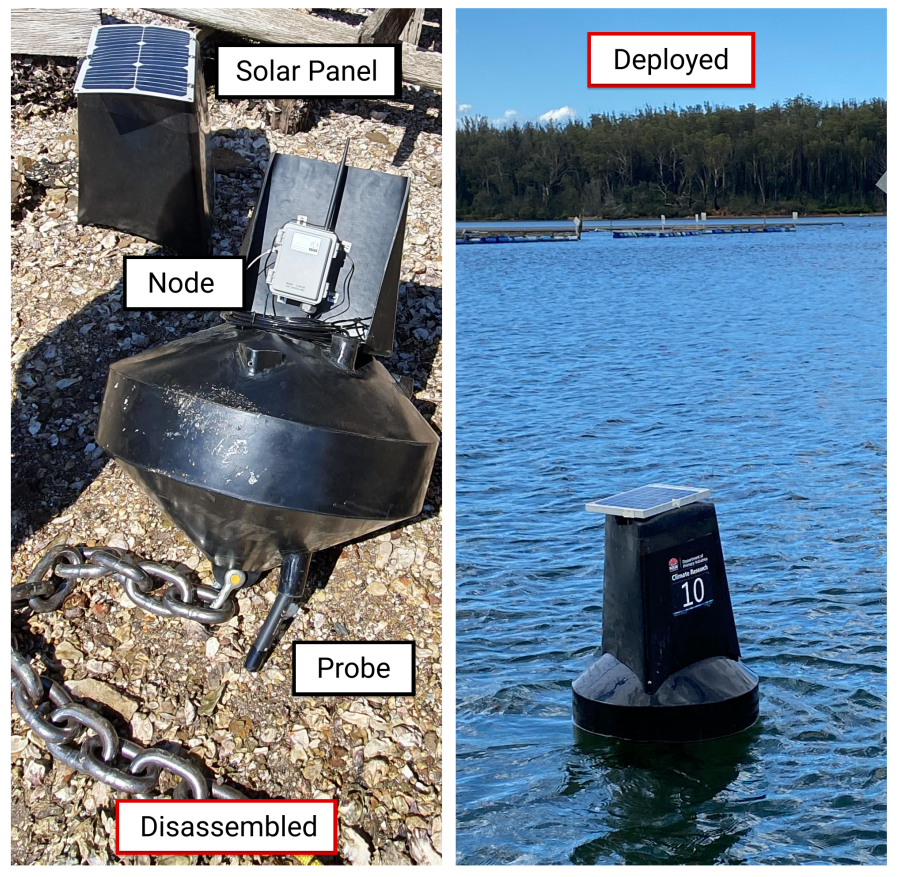

Figure 2. Black research buoy in a disassembled and deployed state on Clyde River. The left image shows a disassembled buoy with a solar panel to recharge a LoRaWAN sensor node. A salinity and temperature sensor (probe) sits underneath the buoy and communicates with the sensor node via a wired SDI-12 interface. 
A LoRaWAN-enabled node (S-Node, ICT International, NSW, AUS) was attached to the top side of each of the buoys. This node features an IP65 enclosure to minimise the possibility of salt degrading electrical components and comes with a $12 \mathrm{~V}$ solar panel for maintaining battery charge. S-Nodes provide a SDI-12 interface for which we connected Ponsel C4E (AquaLabo, FRA) temperature and salinity sensors. These sensors were chosen based on the ease of use, as there are no moving parts, and therefore they can be cleaned easily. To reduce the rate of bio-fouling on the sensors, they were placed in 70 denier stockings (Big-W, NSW, AUS) and secured to the base of the buoy with cable-ties $\sim 40 \mathrm{~cm}$ below the surface of the water (representing the zone where oysters are situated).

Atmospheric weather conditions were assessed at fifteen-minute intervals using an ATMOS 41 automatic weather station (AWS) (Metergroup, NE, USA) connected to an S-Node. This AWS is capable of measuring a range of environmental variables without the use of moving parts such as wind vanes, making it robust enough for remote deployment (see Figure 1 for location). The AWS was situated on a pole away from buildings and trees, as specified by the AWS sitting guidelines provided by the Australian Bureau of Meteorology [28]. However, to represent the conditions the oysters were in, the AWS was placed over water four meters above the high-tide line.

Maintenance was carried out on the buoys and sensors at three-month intervals-as based on previous experience, this length of time was the sufficient to maintain reading accuracy and prevent destructive biofouling. This included scraping barnacles off the buoys, gently cleaning the sensors' measuring heads with a brush or cloth and replacing stockings which covered the sensors. The AWS was maintained according to the same three-month interval, whereby the rainfall cone-a funnel that captures rainfall-had to be cleaned of debris which could block the flow of water through the device's inbuilt rainfall sensor.

\subsection{Software Flow}

Incoming encrypted packets from TTN were automatically processed using a message queuing telemetry transport (MQTT) subscribe script written in bash. This script subscribes to the specific topic that each of the buoys are sending their data over and forwards the encrypted packets of data for storage (backup) and decoding using a combination of php and JavaScript. The decrypted data are then transferred to both ThingSpeak (MathWorks, MA, USA) and ThingsBoard (ThingsBoard, NY, USA) for redundancy measures.

For ease of graphical visualisation, an application programming interface (API) was developed to operate on-top of the ThingsBoard API. This API is called through a WordPress (Automattic, SF, USA) site, known as FarmDecisionTECH ${ }^{\circledR}$, and was plotted using ChartJS [29]. Oyster farmers can access this website using both mobile and desktop devices (Figure 3). The former is particularly important for oyster farmers, as they commonly check sensor readings while on the river and away from desktop computers. Based on view analytics on the FarmDecisionTECH ${ }^{\circledR}$ website, $\sim 60 \%$ of users access the dashboard via their phone.

FarmDecisionTECH ${ }^{\circledR}$ also provides the ability for farmers to create custom alerts when environmental readings (such as temperature or salinity) exceed custom thresholds. Additionally, oyster farmers were given private LoRaWAN temperature monitors for their oyster leases such that only they (or others with permissions) could access their data. This allows the oyster farmers to target oysters that are particularity vulnerable, such as young spats or sensitive species, while maintaining confidentiality on their locations. 


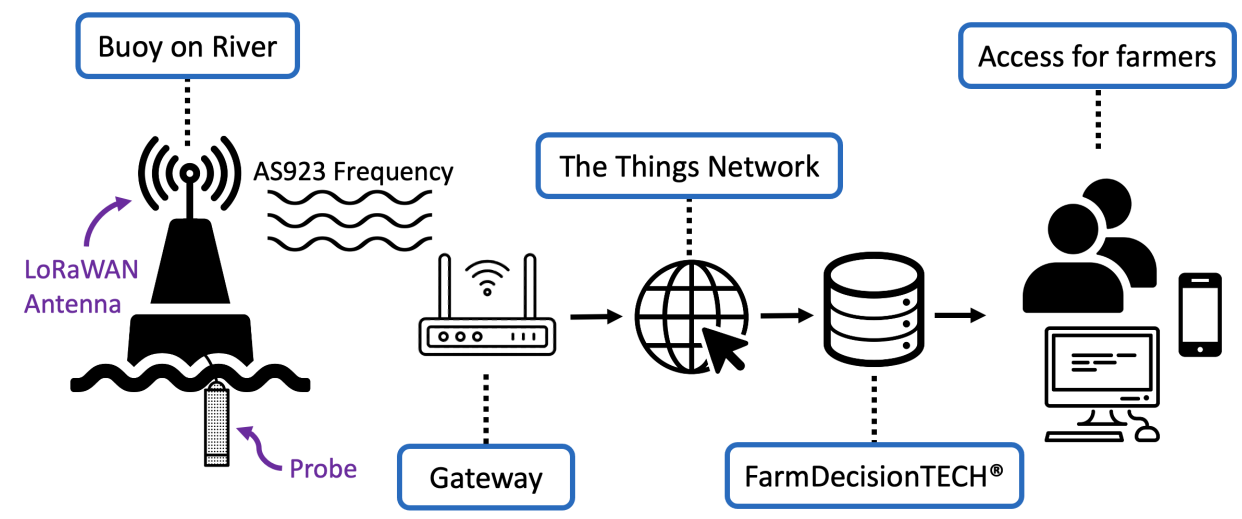

Figure 3. Flow of data from buoy to end-user. From the left, a buoy reads environmental variables from a submerged probe. These data are then transmitted over the AS923 frequency plan (from 921.8 to $923.4 \mathrm{MHz}$ ) to a local LoRaWAN gateway. The gateway forwards data over the Internet to TTN and into FarmDecisionTECH ${ }^{\circledR}$. This website is then accessed by farmers and other end-users on mobile and desktop devices.

\subsection{LoRaWAN Performance}

While LoRaWAN provides several benefits, this technology when applied to our application resulted in a number of lost packets of data. Lost data describes uplinks which were transmitted by a LoRaWAN node but not received by the LoRaWAN gateway. This can occur for several technical and environmental reasons and is often a result of poor received signal strength indicator (RSSI) values and signal-to-noise ratios (SNR) [30,31]. Figure 4 demonstrates the instances of packet loss and other downtime over the operating time of this sensor network. Buoys 1 and 10 were deployed first, followed by 4, 5, 8, 11 and 12, with Buoy 3 and 13 being deployed in mid 2020. Packet loss occurs somewhat randomly with the maximum amount of lost messages being $~ 20 \%$ from Buoy 13 . This buoy is surrounded by large hills and has no clear line of sight to any gateway resulting in low RSSI which could explain the poor message transmission. Although only $\sim 80 \%$ of data were received successfully, the randomness of this downtime allowed gaps in these data to be filled with different forms of interpolation. Two buoys suffered from long periods of downtime. Buoy 1 broke from its sea floor attachment during a large rainfall event in August of 2020, and Buoy 12 suffered from a sensor failure.

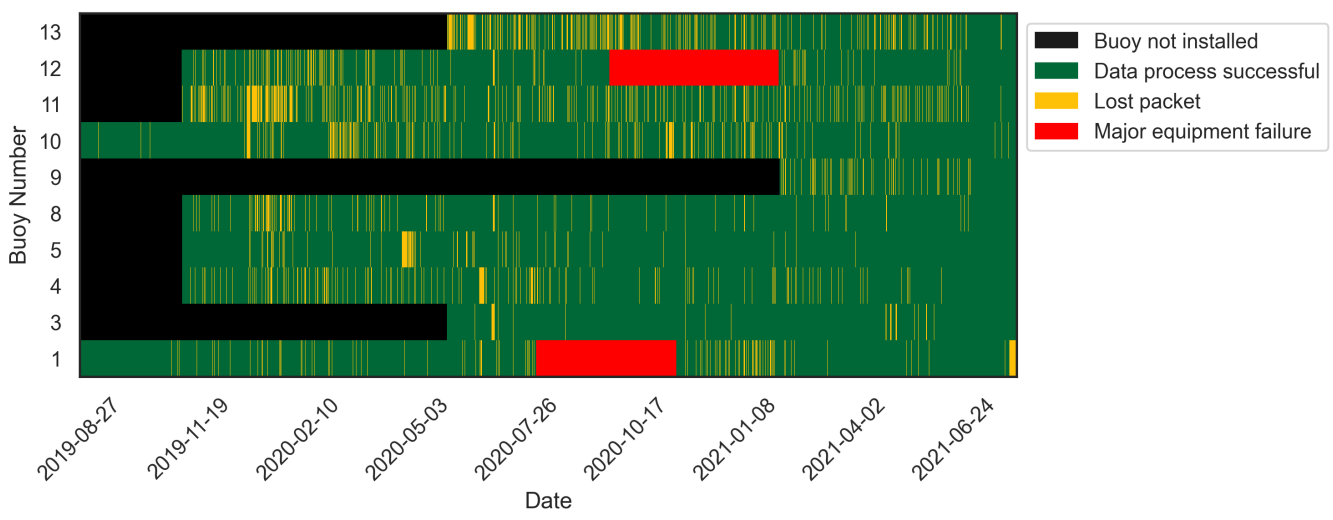

Figure 4. Operational information regarding each of the buoys across Clyde River. Black regions represent time before the buoy was installed, green represents data that were successfully sent and received; orange represents times when data were meant to be send and received but were not; and red indicates times when there was major equipment failure.

The LoRaWAN devices that are employed on Clyde River operate on different phases (i.e., the sampling time does not exactly match between buoys). This creates issues for data 
analysis, as environmental readings from multiple buoys must be processed by rounding each time stamp to the nearest hour. An hour was chosen, as on fifteen-minute sampling intervals each device is given four opportunities to successfully send at least one packet to a LoRaWAN gateway. If there were still missing data for a particular time stamp, an interpolation was applied to fill in any missing values.

\subsection{Local Weather}

As heat waves are detrimental to oysters' survival, a local weather station was deployed to track extreme weather events in real-time [6]. Figure 5 shows both atmospheric (air) temperature and water temperatures on Clyde River during the summer months (December 2020-March 2021). This date range represents the period of time where oysters are most vulnerable to extreme weather events, such as heat waves. Over this three month period there were multiple occasions where air temperature entered a dangerous zone $\left(\geq 30^{\circ} \mathrm{C}\right)$ where oyster mortality was possible if proper management practices were not implemented by oyster farmers [6]. Most notably, there was a seven day period (highlighted as an an insert in Figure 5) where the maximum daily air temperature exceeded $30^{\circ} \mathrm{C}$. This period of high air temperature coincides with a rise in water temperature to a maximum reading of $27.99 \pm 0.44{ }^{\circ} \mathrm{C}$.

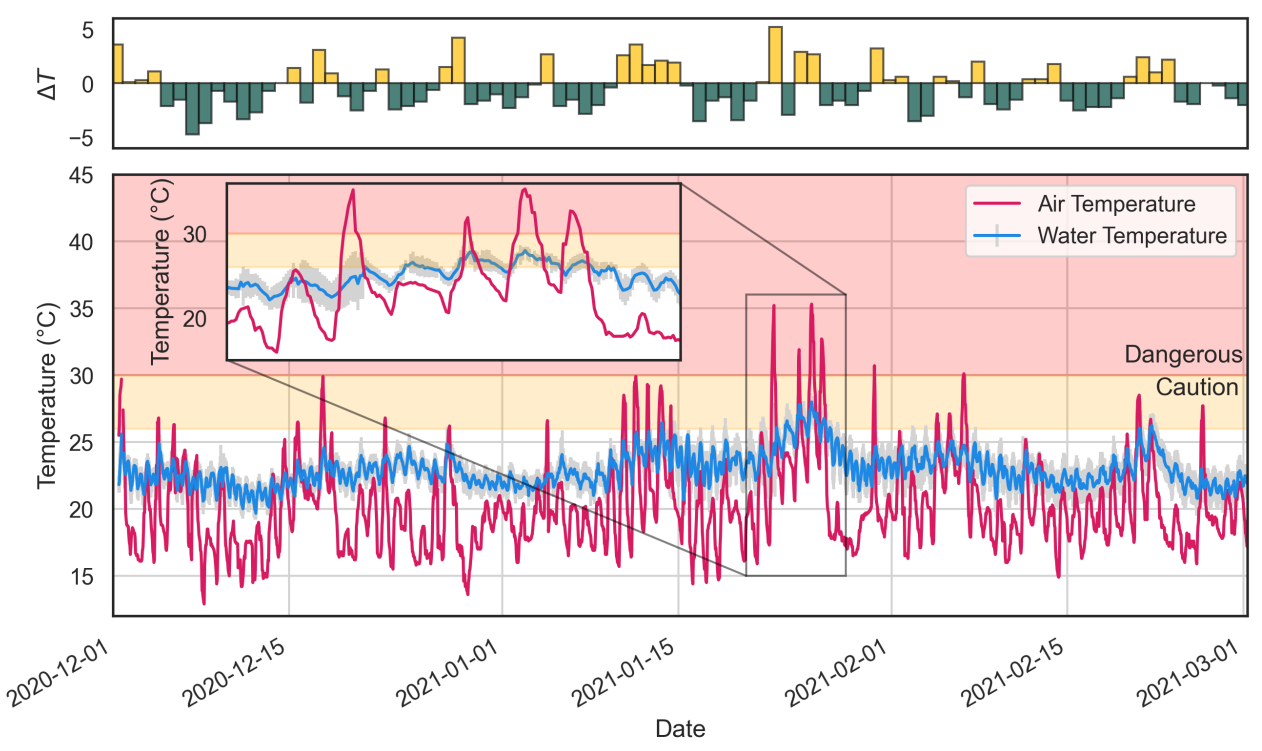

Figure 5. Air (pink line) and water (blue line) temperatures on Clyde River during the summer months (December 2020 to March 2021). Water temperature is the average of all ten buoys \pm the standard deviation. Air temperature was captured using an AWS located on Budd Island. Background colours are used to represent temperatures above $26^{\circ} \mathrm{C}$ (orange) and above $30^{\circ} \mathrm{C}$ (red). The insert depicts a zoomed-in area of interest. Bar chart above main figure demonstrates the difference between $(\Delta T)$ the temperatures recorded at Moruya Airport and at Budd Island. Yellow indicates higher temperatures at Batemans Bay, green indicates lower.

Shown in the upper part of Figure 5 is a comparison between the local real-time Bureau of Meteorology (BoM) weather station located at Moruya Airport and the AWS deployed at Batemans Bay (see Figure 1 for location). These data represent the differences between the maximum temperature each day over the summer months at Batemans Bay $\left(T_{B B}\right)$ and the maximum temperature at Moruya Airport $\left(T_{M Y A}\right)$ for the same day:

$$
\Delta T=\max \left(T_{B B}\right)-\max \left(T_{M Y A}\right)
$$

The data featured in Figure 5 indicate that the maximum temperature at Batemans Bay (i.e., where the oyster leases are located) can be $\sim 5^{\circ} \mathrm{C}$ higher than temperatures recorded at Mouyra Airport. There are BoM weather stations located closer to Batemans Bay, one at 
Nelligen ( $~ 8 \mathrm{~km}$ from Batemans Bay) and another at Batemans Bay Catlina Country Club. However, these sites do not offer real-time data and therefore do not provide information for oyster farmers to make informed decisions with. Additionally, neither of the BoM weather stations reflected the intensity of the heat waves featured in Figure 5.

\subsection{Harvesting}

Regulations overseen by NSW Food Authority dictate that salinity in each of the harvesting areas must exceed a set threshold before harvest area openings can be assessed (Table A1). This threshold is harvest area-specific. Moonlight and Rocky Point require salinity readings $\geq 22 \mathrm{~g} / \mathrm{kg}$. Waterfall, however, requires $\geq 23 \mathrm{~g} / \mathrm{kg}$ (locations found in Figure 1). The limits are based upon assessments of microbiological data under a range of environmental conditions-in accordance with the national standard [32].

Figure 6 illustrates the proportions of time for which the harvest areas have met the salinity criteria from Table A1. Moonlight, which includes Buoys 1, 3, 4 and 5, had the highest harvest open time of $81 \%$. Moving up the river to Rocky Point (Buoys 8 and 9 ), the percentage of compliance with salinity criteria was only $\sim 66 \%$. Finally, Waterfall harvesting area (Buoys 10-13) has seen the least compliance with salinity criteria ( $\sim 55 \%)$. This is to be expected, with saline water being cycled through the river system from Clyde River's entrance at Batemans Bay (adjacent to Moonlight harvesting area).

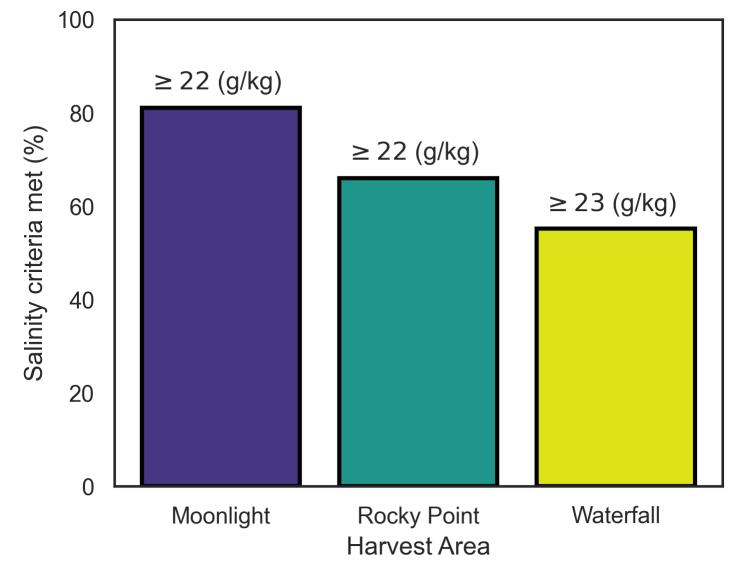

Figure 6. Representation of the percentages of time the harvesting locations have spent in compliance with salinity criteria (see Table A1 for criteria). These percentages were calculated from the average low-tide salinity readings at each harvest area since the network's deployment. Moonlight and Rocky Point must have salinity readings of $\geq 22 \mathrm{~g} / \mathrm{kg}$, whereas Waterfall's salinity must be $\geq 23 \mathrm{~g} / \mathrm{kg}$.

The calculated values featured in Figure 6 only represent closures related to salinity; however, the NSW Food Authority, as demonstrated in Table A1, close harvest areas for various reasons, including high E. coli concentrations and faecal coliform counts. However, the presence of bacteria such as E. coli is generally higher when oysters are situated in low salinity water [33]. Therefore, salinity is suitable for use as a baseline indicator of the state of the river.

\subsection{Spatial Interpolation}

As the sensor network is primarily aimed at increasing oyster farmers' capacity to make informed farm management decisions, the focus was on presenting these data in an informative and clear manner. Typical two-dimensional representations-such as Figure 5-often fail to portray spatial differences in environmental variables. As these data represent a reasonably complex three-dimensional structure, with ten buoys spatially distributed (spatial-dimension) on fifteen-minute (temporal-dimension) environmental sampling intervals (environmental-dimension), a Python (Version 3.9.5) program was created to formulate heat maps which encompass all these variables [34]. This script uses 
either $n$ data points or a date range of values captured from all buoys to create an array of maps which are then transformed into a graphical interchange file (gif).

Each heat map consists of a spatially interpolated image of salinity (though any environmental variable could be substituted here) readings from all buoys operating on Clyde River with an overlay image captured from OpenStreetMap to visualise the river's shape [35]. Spatial interpolation is commonly used to infer environmental variables across a water body [36]. The resolution of the spatial interpolation was set to 100 (i.e., 100 values between the maximum and minimum latitude and longitude), as this value provided a balance between computation time and visual aesthetics. As this method cannot interpolate outside of the bounds of the buoys, maximum and minimum latitude and longitude, two virtual data points were used for the desired mapping extent with values related to the closest buoys' actual readings (i.e., Buoy 13 for a virtual reading in the top left of the map and Buoy 1 for the bottom right).

The heat maps featured in Figure 7 demonstrate the effects that large rainfall events can have on Clyde River. Three dates were chosen from March 2021 (19, 20 and 21) which represent the collapse in salinity after a significant flooding event. Buoys located further up the river system experienced declines in salinity sooner than those located close to the rivers mouth (at Batemans Bay), represented as a change in colour from green to red. The heat map representing the state of the river on March 20 indicates that salinity was lower around Buoys 11 and 12, which are located at the exit of a major freshwater tributaryBuckenbowra River. For the 21 of March, the entire Clyde River oyster farming region is represented in red, meaning salinity readings of less than $\sim 5 \mathrm{~g} / \mathrm{kg}$.

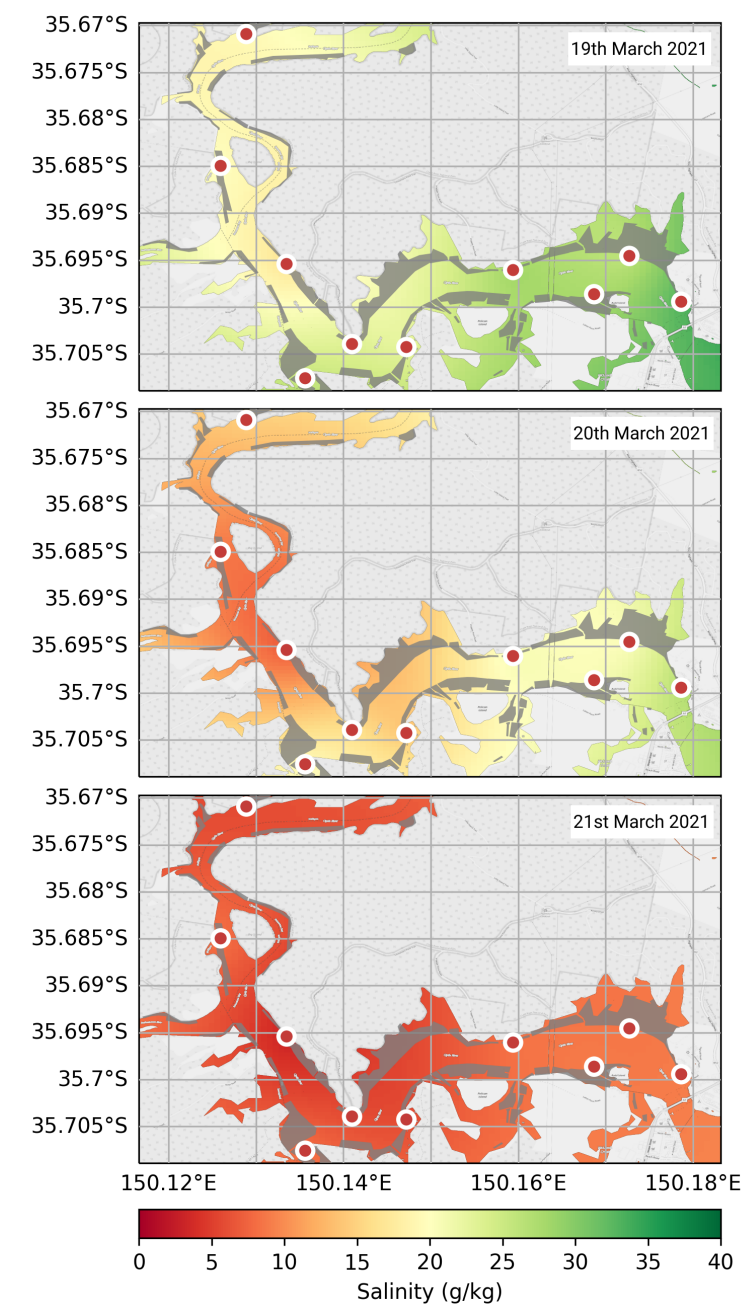

Figure 7. Heat map view of salinity in Clyde River. Colour is used to represent salinity from 0 to $40 \mathrm{~g} / \mathrm{kg}$ 
(red and green, respectively). Buoys are represented as red circles with white edges (see Figure 1 for labels). Each consecutive map (from top) represents a $24 \mathrm{~h}$ increase in time from the 19 to 21 March 2021. This date range demonstrates the change in salinity on Clyde River after a major rainfall event.

\section{Discussion}

This work describes the deployment of a LoRaWAN-enabled sensor network for monitoring both water quality and atmospheric conditions on Clyde River located on the southern coast of NSW, Australia. These data are provided in real-time to oyster farmers operating on the river through a self-hosted data platform known as FarmDecisionTECH ${ }^{\circledR}$, assisting them in making informed farm management decisions and preventing the loss of oyster leases due to extreme weather events-such as flooding and heat waves. The methods shown in this work represent an end-to-end approach of assisting the aquaculture industry through the use of newly available digital technologies. This differs from other approaches which focus on technological aspects of deploying aquaculture monitoring sensors $[26,27,37]$.

The use of LoRaWAN as a means to communicate sensor data from remote buoys located throughout the river system was integral in ensuring that the entire oyster farming region was represented. There were, however, several problems related to packet loss that presented issues for data analysis, as gaps in data were common, occurring about $20 \%$ of the time over the operating period of the buoy in some instances (Figure 4). This could be solved in post-processing through interpolation; however, this issue may be relegated in the future using message acknowledgement techniques, which have been shown to reduce packet loss to as little as 5\% [30]. Additionally, issues created from the LoRaWAN nodes operating on different sampling intervals (phases) could be solved by configuring them to measure at set times (12:00, 12:15, etc.).

The sensor network was deployed in collaboration with oyster farmers as a means to increase their use of valuable digital technologies. A major part of this was the deployment of a real-time weather station, as prior to its installation the oyster farmers were dependent on Mouyra Airport for live weather updates (see Figure 1 for location). As demonstrated in Figure 5, Mouyra Airport was $\sim 5^{\circ} \mathrm{C}$ cooler than Clyde River AWS during a heat wave event at the start of 2021. This may be a result of Moruya Airport's coastal location, which may be cooled by Northeasterly seabreezes that frequent the east coast of NSW during summer months [38]. Clyde River, on the other hand, is shielded by these seabreezes, which may result in higher temperatures. These temperatures have the potential to kill oysters if they are left exposed, resulting in a substantial loss of income [6]. Interestingly, the coupling of surface air temperature and surface water temperature demonstrates that frequent heat waves could result in surface water temperatures above $30{ }^{\circ} \mathrm{C}$ (Figure 5). This would have an impact on oyster farmers, as the current method to protect their leases is to ensure all oysters are submerged in the event of a heat wave. However, if water temperatures exceed $30^{\circ} \mathrm{C}$, this method may prove ineffective. This could be exacerbated under a changing climate: extreme weather events, such as heat waves, are predicted to increase in frequency and intensity [39]. During this three month period (Dec-Feb) there were 378 unique page views on the FarmDecisionTECH ${ }^{\circledR}$ Clyde River dashboard, which represents a substantial number of views considering there are $\sim 17$ growers operating on the river.

In addition to responding to extreme weather events, real-time in situ data can also be used for basic day-to-day decisions. This includes the monitoring of low to moderate intensity rainfall and its effect on particular harvesting areas. These data and representations such as Figure 6 also help with an important aspect of oyster farming-risk management. New oyster farmers could use these data to determine the suitability of particular oyster growing regions, in terms of how often these regions are generally open for harvesting. Existing farmers can use these data to determine where their particularly vulnerable oysters should be distributed amongst their leases. 
Communicating environmental information to farmers was also seen as a major priority in the deployment of this infrastructure. Oyster farmers are intrinsically tied to environmental conditions through their daily operations, and to harvesting regulations laid out by NSW Food Authority (Table A1). The typical protocol for closing harvesting areas depends on a number of variables, including, rainfall, bacteria count, faecal coliform count and salinity. The latter is easier to measure in situ and therefore can be provided in real-time through graphical visualisations such as Figure 7. The NSW Food Authority requires physical sampling around mid-ebb tide; however, sensor networks, such as the one described in this work, could be adopted as an official method of assessing the state of the river-subject to approval. These in situ measurements could speed up these processes and allow oyster farmers to resume harvesting soon after the river has recovered.

While Figure 7 provides a clear and informative view on the state of Clyde River for oyster farmers, there are several problems with this representation that need to be addressed. (1) The map does not represent currents and eddies that may be influencing the river. (2) The interpolation does not occur outside the bounds of the buoys' spatial locations; therefore, virtual data points are placed to delimit the desired map size, which use data from the closest buoys. (3) This interpolation only represents the upper $\sim 40 \mathrm{~cm}$ of water; however, this region is where oysters are located. (4) The environmental measurements must have sufficient spatial resolution. While these problems exist, our heat maps still provide valuable rapid representations of the state of a river for oyster farmers. The example shown in Figure 7 demonstrates the change in salinity in Clyde River after a major rainfall event. Two major tributaries include Buckenbowra River (entering Clyde River around Buoy 11), and $\sim 30 \mathrm{~km}$ further up, Clyde River at Brooman. As can be seen from Figure 7, on the 20 March 2021, Buoys 11 and 12 were lower in salinity than Buoy 13, indicating that significant flow was occurring from Buckenbowra River and that flow from upstream tributaries had not reached Buoy 13. The following day (21 March), the entire Clyde River was inundated with freshwater, resulting in a decline in salinity. The use of in situ sensors does allow oyster farmers the ability to monitor the river's state and can provide a quantitative assessment on its subsequent recovery so farming operations can return to normal.

\section{Conclusions}

This work has described the deployment of a real-time sensor network to monitor environmental conditions on Clyde River. Data captured from this network have been used to enhance farm management decisions of oyster farmers operating on the river. The use of relatively low-cost in situ sensors has proven to be an essential asset to ensure oyster farmers have both current and accurate information with which to make decisions. Undoubtedly, the use of LoRaWAN and other IoT systems has made the deployment of this sensor network possible. Other oyster farming regions could benefit from similar infrastructure, and it could provide valuable information needed to help farmers adapt to the changing climate.

To increase the ability for oyster farmers to make informed farm management decisions, subsequent works could focus on predicting future environmental conditions. This would allow farmers to prepare for flooding or heat wave events and take preventive measures before the onset of such conditions. Additionally, the sensors deployed in this work only provide basic environmental variables, such as temperature and salinity. However, as mentioned throughout this work, other factors, such as phytoplankton blooms, bacteria and coliform faecal count, play large roles in how oyster farmers operate. This presents opportunities for new in situ environmental sensors that can assess these variables in real-time [40,41]. 
Author Contributions: Conceptualisation, M.P., A.B. and H.B.; methodology, M.P., A.B. and H.B.; software, H.B.; validation, H.B., M.P. and A.B.; formal analysis, H.B., M.P. and A.B.; investigation, H.B. and M.P.; resources, A.B. and M.P.; data curation, A.B., M.P. and H.B.; writing-original draft preparation, H.B. and M.P.; writing-review and editing, M.P. and A.B.; visualisation, H.B.; supervision, A.B.; project administration, M.P. and A.B.; funding acquisition, A.B. All authors have read and agreed to the published version of the manuscript.

Funding: This research was funded by NSW Department of Primary Industries and the NSW Office of Environment and Heritage through the NSW Primary Industries Climate Change Research Strategy. It is part of the Climate Smart Pilots program in the Resilience theme of the strategy.

Acknowledgments: The authors also acknowledge the assistance of the NSW Food Authority and Eurobodalla Shire Council.

Conflicts of Interest: The authors declare no conflict of interest.

\begin{tabular}{|c|c|}
\hline \multicolumn{2}{|c|}{ Abbreviations } \\
\hline The follon & g abbreviations are used in this manuscript: \\
\hline API & Application programming interface \\
\hline AWS & Automatic weather station \\
\hline BoM & Bureau of Meteorology \\
\hline FCC & Faecal coliform count \\
\hline GIF & Graphical interchange file \\
\hline IALA & International Association of Marine Aids to Navigation and Lighthouse Authorities \\
\hline IoT & Internet of Things \\
\hline JSON & Java script object notation \\
\hline LPWAN & Low power wide area network \\
\hline LoRaWAN & Low power, long range, wireless area network \\
\hline MQTT & Message queuing telemetry transport \\
\hline NB-IoT & Narrow-band Internet of Things \\
\hline NSW & New South Wales \\
\hline RSSI & Received signal strength indicator \\
\hline SNR & Signal-to-noise ratio \\
\hline TTN & The Things Network \\
\hline
\end{tabular}

\section{Appendix A}

Table A1. NSW Food Authority (unpublished) operational criteria for harvest area management on Clyde River.

\begin{tabular}{cccccc}
\hline Harvest Zone & 24 h Rainfall $(\mathbf{m m}) *$ & 7 day Rainfall $(\mathbf{m m})$ & FCC $(\mathbf{c f u} / \mathbf{1 0 0} \mathbf{~ m L})$ & Bacteria $($ E. coli/g) & Salinity $(\mathrm{g} / \mathbf{k g})$ \\
\hline Moonlight & 30 & 100 & $\leq 14$ or $\leq 70 * *$ & $\leq 2.3$ or $\leq 46^{* *}$ & $\geq 22$ or $>18^{* *}$ \\
Rocky Point & 40 & 100 & $\leq 14$ & $\leq 2.3$ & $\geq 22$ \\
Waterfall & 40 & 100 & $\leq 14$ & $\leq 2.3$ & $\geq 23$ \\
\hline
\end{tabular}

* Rainfall must be $\leq 10 \%$ of weekly closure limit after sampling to open harvesting. ${ }^{* *}$ Restricted opening, oysters must undergo depuration in high quality water to purge contaminants. Note: Opening of harvesting areas also depends on other environmental assessments, such as phytoplankton sampling and identification.

\section{References}

1. Bayne, B.L. Biology of Oysters; Academic Press: Cambridge, MA, USA, 2017.

2. Paget, N.; Daniell, K.A.; Rubio Zuazo, A.; Barreteau, O. Environmental information sharing: a means to support the legitimization of oyster farmers' stewardship over water quality management in NSW, Australia. Nat. Resour. Forum 2016, 40, 21-36. [CrossRef]

3. FAO. The State of World Fisheries and Aquaculture, FAO, Sustainability in Action; Technical Report; United Nations: Rome, Italy, 2020. [CrossRef]

4. David, M.; Amara H.S.; Robert, C.; Michael, D. Australian Fisheries and Aquaculture, Outlook to 2025-26; Technical Report; Australian Bureau of Agricultural and Resource Economics and Sciences: Canberra, Australia, 2021. Available online: https:/ / www.researchgate.net/publication/349703558_Australian_fisheries_and_aquaculture_Outlook_to_2025-26 (accessed on 28 November 2021). 
5. Edith, G. Aquaculture Production Report; Technical Report; NSW Department of Primary Industries: Orange, Australia, 2021. Available online: https://www.dpi.nsw.gov.au/fishing/aquaculture/publications/aquaculture-production-reports (accessed on 28 November 2021).

6. Nell, J.A. The history of oyster farming in Australia. Mar. Fish. Rev. 2001, 63, 14-25.

7. Schrobback, P.; Coglan, L.; Pascoe, S. Socio-economic determinants for industry development: The case of Australia's Sydney rock oyster industry. Aquat. Living Resour. 2014, 27, 167-175. [CrossRef]

8. Schrobback, P.; Pascoe, S.; Coglan, L. History, status and future of Australia's native Sydney rock oyster industry. Aquat. Living Resour. 2014, 27, 153-165. [CrossRef]

9. Pernet, F.; Lupo, C.; Bacher, C.; Whittington, R.J. Infectious diseases in oyster aquaculture require a new integrated approach Philos. Trans. R. Soc. Biol. Sci. 2016, 371, 20150213. [CrossRef]

10. Webby, R.J.; Carville, K.S.; Kirk, M.D.; Greening, G.; Ratcliff, R.M.; Crerar, S.K.; Dempsey, K.; Sarna, M.; Stafford, R.; Patel, M.; et al. Internationally distributed frozen oyster meat causing multiple outbreaks of norovirus infection in Australia. Clin. Infect. Dis. 2007, 44, 1026-1031. [CrossRef]

11. Ogburn, D.M.; White, I.; McPhee, D.P. The disappearance of oyster reefs from eastern Australian estuaries-Impact of colonial settlement or mudworm invasion? Coast. Manag. 2007, 35, 271-287. [CrossRef]

12. Potter, M.; Hill, B. Heat mortality in the Sydney rock oyster, Saccostrea (Crassostrea) commercialis and the effectiveness of some control methods. Aquaculture 1982, 29, 101-108. [CrossRef]

13. Losasso, C.; Bille, L.; Patuzzi, I.; Lorenzetto, M.; Binato, G.; Dalla Pozza, M.; Ferrè, N.; Ricci, A. Possible influence of natural events on heavy metals exposure from shellfish consumption: A case study in the north-east of Italy. Front. Public Health 2015, 3, 21. [CrossRef]

14. Ajani, P.A.; Verma, A.; Kim, J.H.; Woodcock, S.; Nishimura, T.; Farrell, H.; Zammit, A.; Brett, S.; Murray, S.A. Using qPCR and high-resolution sensor data to model a multi-species Pseudo-nitzschia (Bacillariophyceae) bloom in southeastern Australia. Harmful Algae 2021, 108, 102095. [CrossRef]

15. Dame, R.F.; Kenneth, M.J. Ecology of Marine Bivalves: An Ecosystem Approach; Taylor \& Francis: Abingdon, UK 2011.

16. Varandas, L.; Faria, J.; Gaspar, P.D.; Aguiar, M.L. Low-cost IoT remote sensor mesh for large-scale orchard monitorization. J. Sens. Actuator Netws. 2020, 9, 44. [CrossRef]

17. Fuentes-Pérez, J.F.; Sanz-Ronda, F.J. A Custom Sensor Network for Autonomous Water Quality Assessment in Fish Farms. Electronics 2021, 10, 2192. [CrossRef]

18. Sforza, F. Communications System. U.S. Patent 8,406,275, 26 March 2013

19. Alliance, LoRa. LoRaWAN R1.0 Open Standard Released for the IoT. Available online: https://www.businesswire.com/news/ home/20150616006550/en/LoRaWAN-R1.0-Open-Standard-Released-IoT (accessed on 28 Novemver 2021).

20. Basford, P.J.; Bulot, F.M.; Apetroaie-Cristea, M.; Cox, S.J.; Ossont, S.J. LoRaWAN for smart city IoT deployments: A long term evaluation. Sensors 2020, 20, 648. [CrossRef]

21. Codeluppi, G.; Cilfone, A.; Davoli, L.; Ferrari, G. LoRaFarM: A LoRaWAN-based smart farming modular IoT architecture. Sensors 2020, 20, 2028. [CrossRef]

22. Tolentino, L.K.; Chua, E.J.; Añover, J.R.; Cabrera, C.; Hizon, C.A.; Mallari, J.G.; Mamenta, J.; Quijano, J.F.; Virrey, G.; Madrigal, G.A.; et al. IoT-Based Automated Water Monitoring and Correcting Modular Device via LoRaWAN for Aquaculture. Int. J. Comput. Digit. Syst. 2021, 10, 533-544. [CrossRef]

23. Mekki, K.; Bajic, E.; Chaxel, F.; Meyer, F. Overview of cellular LPWAN technologies for IoT deployment: Sigfox, LoRaWAN, and NB-IoT. In Proceedings of the 2018 IEEE International Conference on Pervasive Computing and Communications Workshops (Percom Workshops), Athens, Greece, 19-23 March 2018; pp. 197-202.

24. Delauney, L.; Compere, C.; Lehaitre, M. Biofouling protection for marine environmental sensors. Ocean Sci. $2010,6,503-511$. [CrossRef]

25. Pule, M.; Yahya, A.; Chuma, J. Wireless sensor networks: A survey on monitoring water quality. J. Appl. Res. Technol. 2017, 15, 562-570. [CrossRef]

26. Parri, L.; Parrino, S.; Peruzzi, G.; Pozzebon, A. Offshore LoRaWAN Networking: Transmission Performances Analysis under Different Environmental Conditions. IEEE Trans. Instrum. Meas. 2020, 70, 1-10. [CrossRef]

27. Ortega-Corral, C.; Esqueda Elizondo, J.J.; Acosta Del Campo, O.R.; Palafox, L.E.; Aguilar, L.; Guerra-Frausto, R.; López Cruz, F.; Reyes, R.A.; López-Montoya, J.E.; Chávez, C. Lessons learned deploying an oyster farm monitoring auto-sustainable wireless sensor network and trial of a temperature and relative humidity-based transmission power control scheme. Int. J. Distrib. Sens. Netws. 2017, 13, 1550147717697322. [CrossRef]

28. Transport for NSW. Automatic Weather Stations; Technical Report; NSW Government. Available online: https://roads-waterways transport.nsw.gov.au/business-industry/partners-suppliers/documents/specifications/r272.pdf (accessed on 28 Novemver 2021).

29. Dawnie, N. ChartJS. Available online: https://www.chartjs.org/ (accessed on 28 Novemver 2021).

30. Wang, S.Y.; Chen, T.Y. Increasing lorawan application-layer message delivery success rates. In Proceedings of the 2018 IEEE Symposium on Computers and Communications (ISCC), Natal, Brazil, 25-28 June 2018; pp. 00148-00153.

31. Liu, Q.; Mu, Y.; Zhao, J.; Feng, J.; Wang, B. Characterizing packet loss in city-scale lorawan deployment: Analysis and implications. In Proceedings of the 2020 IFIP Networking Conference (Networking), Paris, France, 22-26 June 2020; pp. $704-712$. 
32. Australian Shellfish Quality Assurance Advisory Committee. The Australian Shellfish Quality Assurance Program; Technical Report; SafeFish. Available online: https:/ / www.safefish.com.au/reports/manuals-and-guidelines/the-australian-shellfish-qualityassurance-program-manual (accessed on 28 Novemver 2021).

33. Rowse, A.J.; Fleet, G.H. Effects of water temperature and salinity on elimination of Salmonella charity and Escherichia coli from Sydney rock oysters (Crassostrea commercialis). Appl. Environ. Microbiol. 1984, 48, 1061-1063. [CrossRef]

34. Bates, H. iot-Spatial-Interpolation. Available online: https://github.com/DPIclimate/iot-spatial-interpolation (accessed on 28 Novemver 2021).

35. OpenStreetMap contributors. Planet Dump. Available online: https:/ / planet.osm.org (accessed on 15 September 2021).

36. Sima, S.; Tajrishy, M. Developing water quality maps of a hyper-saline lake using spatial interpolation methods. Sci. Iran. 2015, $22,30-46$.

37. Ortega-Corral, C.; Palafox, L.E.; García-Macías, J.A.; Sánchez-García, J.; Aguilar, L. End-to-end message exchange in a deployable marine environment hierarchical wireless sensor network. Int. J. Distrib. Sens. Netws. 2014, 10, 950973. [CrossRef]

38. Gibbs, M.T. Detecting a response to weak sea breezes in the New South Wales coastal ocean. N. Z. J. Mar. Freshw. Res. 2000, 34, 669-680. [CrossRef]

39. Stocker, T. Climate Change 2013: The Physical Science Basis: Working Group I Contribution to the Fifth Assessment Report of the Intergovernmental Panel on Climate Change; Cambridge University Press: Cambridge, UK, 2014.

40. Sorensen, J.; Lapworth, D.; Marchant, B.; Nkhuwa, D.; Pedley, S.; Stuart, M.; Bell, R.; Chirwa, M.; Kabika, J.; Liemisa, M.; et al. In-situ tryptophan-like fluorescence: A real-time indicator of faecal contamination in drinking water supplies. Water Res. 2015, 81, 38-46. [CrossRef] [PubMed]

41. Bates, H.; Zavafer, A.; Szabó, M.; Ralph, P.J. A guide to Open-JIP, a low-cost open-source chlorophyll fluorometer. Photosynth. Res. 2019, 142, 361-368. [CrossRef] 